${ }^{7}$ Barchha, R, Stewart, M A, and Guze, S B, American fournal of Psychiatry, $1968,125,681$.

${ }^{8}$ Moore, R A, American fournal of Psychiatry, 1971, 128, 130.

${ }^{9}$ McCusker, J, Cherubin, C, and Zimberg, S, New York State fournal of Medicine, 1971, 71, 751.

10 Gomberg, E S, fournal of Studies on Alcohol, 1975, 36, 1458.

${ }^{11}$ Edwards, G, Chandler, J, and Hensman, C, Quarterly fournal of Studies on Alcohol, 1972, suppl No 6, pp 94, 120.
${ }^{12}$ Hilton, M R, and Lokare, V G, British fournal of Psychiatry, 1978, 132, 42.

13 Plant, M A, and Miller, T I, Social Psychiatry, 1977, 12, 21

14 Kearney, T R, American fournal of Psychiatry, 1969, 125, 157.

${ }_{15}$ Morgan, A W, et al, Canadian Medical Association fournal, 1974, 111, 1067.

${ }^{16}$ Morgan, H G, et al, British fournal of Psychiatry, 1975, 127, 564.

(Accepted 13 fuly 1979)

\title{
Cimetidine in treatment of reflux oesophagitis with peptic stricture
}

\author{
ROGER FERGUSON, M W DRONFIELD, MICHAEL ATKINSON
}

British Medical fournal, 1979, 2, 472-474

\section{Summary and conclusions}

Twenty patients with reflux oesophagitis causing a tight peptic oesophageal stricture entered a randomised double-blind crossover trial in which they received cimetidine, $1.6 \mathrm{~g}$ daily, and matching placebo each for six months. The gross endoscopic appearances of oesophagitis, though not the grades of histopathological changes, showed significant improvement during treatment with cimetidine. The need for dilatation of the strictures, however, was not reduced.

\section{Introduction}

Peptic oesophageal stricture is caused by reflux oesophagitis, whose severity is related to the acidity of the oesophageal contents. ${ }^{1}$ Cimetidine, a potent inhibitor of the secretion of gastric acid and pepsin, reduces oesophageal acidity, ${ }^{2}$ relieves symptoms, ${ }^{34}$ and promotes healing of oesophagitis ${ }^{5}{ }^{6}$ in patients with gastro-oesophageal reflux. To determine whether cimetidine is of benefit in the treatment of peptic oesophageal stricture we have studied its effect on symptoms, oesophagitis, and the need for dilatation in 20 patients with peptic oesophageal stricture resistant to conventional medical management of gastro-oesophageal reflux.

\section{Patients and methods}

Twenty patients, 10 men and 10 women aged $52-82$ years (mean 70 years), entered the study. All had tight oesophageal strictures that, despite conventional medical measures to control reflux, had required at least two dilatations in the preceding six months or three in the preceding year. One patient suffered from systemic sclerosis, three had previously undergone vagotomy and pyloroplasty or a gastric resection for peptic ulcer, and one had undergone a Nissen fundoplication.
University Hospital, Nottingham NG7 2UH

ROGER FERGUSON, MD, MRCP, senior medical registrar MICHAEL ATKINSON, MD, FRCP, consultant physician $M$ W DRONFIELD, MB, MRCP, senior medical registrar
Trial design-Cimetidine (400 $\mathrm{mg}$ four times daily) was compared with a placebo on a double-blind crossover basis, the preparations being given for six months each in random order. Symptoms, endoscopic and histopathological appearances, and the need for dilatation were recorded.

Symptoms-The occurrence of pain and the severity of dysphagia were recorded daily by the patients on a diary card, which they brought to the clinic on each monthly visit. Dysphagia was graded as the ability to swallow a normal diet (grade 0), a diet avoiding only certain solids such as steak or raw fruit (grade 1), a soft diet (grade 2), and a liquid diet (grade 3 ); those with grade 4 dysphagia had difficulty in taking even liquids in adequate amounts. All patients were weighed monthly in the clinic and throughout the trial took an antacid (Asilone Gel) as required for pain and were asked to sleep with the bed-head raised.

Endoscopy-The upper alimentary tract was examined using the Olympus GIFK fibreoptic endoscope at the beginning, after two months, and at the end of each six-month treatment period and whenever dysphagia became severe. The diameter of the stricture was measured and the degree of oesophagitis in the stricture assessed using a grading scale of 0 for normal mucosa, 1 for reddening, 2 for reddening and friability to touch, and 3 for ulceration.

Histopathology-Biopsy specimens from within the stricture were taken at endoscopy, and the degree of oesophagitis was graded histopathologically as normal (grade 0), mild inflammatory cell infiltration (grade 1), severe inflammatory cell infiltration (grade 2), and ulceration (grade 3).

Dilatation-Dilatation of the stricture using the Eder Puestow metal olive dilators was done only when the stricture failed to admit the Olympus GIFK endoscope (external diameter $12.5 \mathrm{~mm}$ ).

\section{Results}

Fourteen of the 20 patients completed the full trial: five died during the trial (of whom three had completed at least six months) and one was withdrawn after six months. In all, 16 treatments with cimetidine and 16 with placebo were completed.

Symptomatic response-The average number of days and nights per month during which pain occurred was 6.8 for the six months of placebo treatment and $4 \cdot 1$ for the six months of cimetidine treatment. This difference was not significant, but since the maximum score possible was 56 pain was apparently not a troublesome symptom. The grade of dysphagia at the end of each month averaged 0.45 for placebo and 0.76 for cimetidine. This difference was not significant.

Endoscopic appearances-On entering the trial all patients had intense oesophagitis with ulceration in the stricture (grade 3). To assess the change in the gross endoscopic appearances the grade of oesophagitis at the beginning was subtracted from that at the end of each treatment period (fig 1). The degree of oesophagitis improved significantly during cimetidine treatment compared with placebo treatment $(P<0.05)$. During cimetidine treatment 10 of the 16 patients improved and one deteriorated, while during placebo treatment five improved and five deteriorated. 


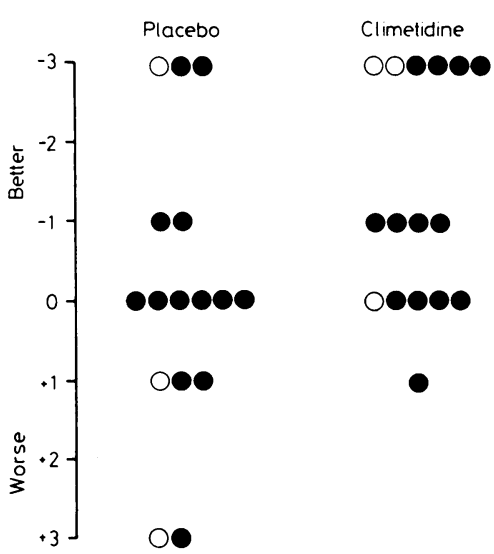

FIG 1-Cnange in grade of oesophagitis as assessed from gross endoscopic appearances during 16 cimetidine and 16 placebo treatment periods. (Open circles represent those patients who had undergone vagotomy and drainage or gastric resection for peptic ulcer.)

Histopathology-Subtracting the histopathological grade of oesophagitis seen in the endoscopic biopsy specimen at the beginning from that at the end of each treatment period showed no significant improvement in oesophagitis during treatment with cimetidine compared with placebo treatment (fig 2). Some difficulty was encountered in this procedure, however, since at times gastric-type epithelium was obtained on biopsy within the stricture and it was difficult to compare this with previous biopsy specimens in which squamous epithelium had been present.

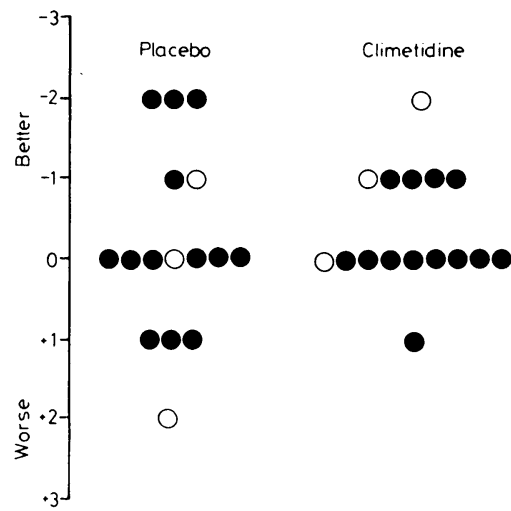

FIG 2-Change in grade of oesophagitis as assessed from histological appearances of oesophageal biopsy specimens taken during 16 cimetidine and 16 placebo treatment periods. (Open circles represent those patients who had undergone vagotomy and drainage or gastric resection for peptic ulcer.)

Dilatation-During the six months before entry into the trial the average number of dilatations required in each patient was $2 \cdot 0$. This fell during the trial to an average of 1.25 with placebo treatment and 1.12 with cimetidine treatment. Dilatation was not necessary during nine of the 16 cimetidine and five of the 16 placebo treatment periods. When the number of dilatations in each period in individual patients are compared (fig 3) five required fewer and two required more dilatations during cimetidine treatment. The three patients who had undergone a vagotomy and drainage procedure or gastric resection all required frequent dilatations during both treatment periods, even though the oesophagitis improved in two. Thus we were unable to show any significant reduction in the need for dilatation of peptic stricture during the trial in spite of the improvement in oesophagitis.

Side effects and deaths-No patient reported any side effects from cimetidine, and routine blood samples taken at monthly intervals showed a slight rise in serum creatinine concentration during cimetidine treatment but no change in liver function tests nor any haematological abnormality. Of the five deaths during the trial, two resulted from cardiac infarction: one occurred four months after the patient had completed the six-month course of cimetidine and one on initial placebo treatment. Both patients had had pre-existent angina. One patient died of a cerebral haemorrhage after completing six months' cimetidine treatment, one of bronchopneumonia and inanition during an initial placebo period, and the fifth, a woman with systemic sclerosis affecting most of the gut, died of peritonitis after perforation of a stercoral ulcer of the colon after six months' cimetidine treatment. It seemed improbable that any of these deaths were attributable to cimetidine.

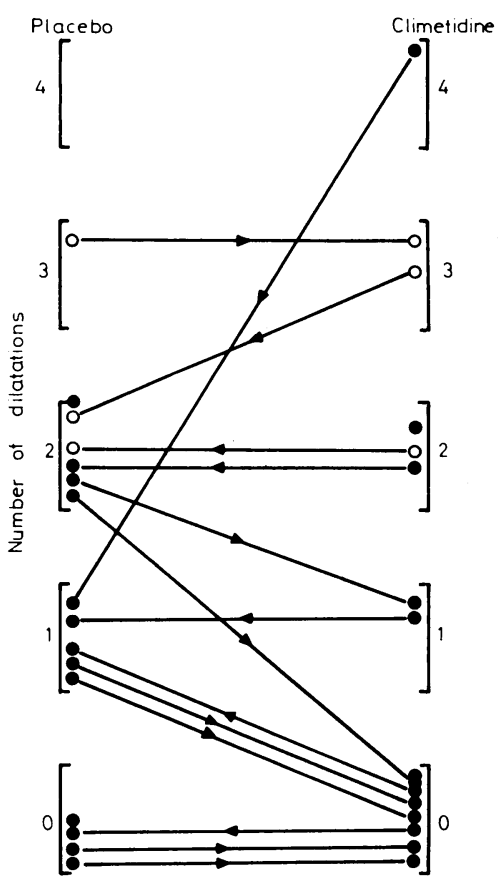

FIG 3-Numbers of dilatations needed during cimetidine and placebo treatment periods in individual patients. The arrows indicate the order in which treatment was received. (Open circles represent those patients who had undergone vagotomy and drainage or gastric resection for peptic ulcer.)

\section{Discussion}

The value of cimetidine in relieving symptoms of gastrooesophageal reflux is now generally accepted, but whether it promotes healing of oesophagitis is less certain. With treatment periods of six to eight months neither Behar et $a l^{3}$ nor PowellJackson et $a l^{4}$ could show any improvement in oesophagitis, although, after giving $1.6 \mathrm{~g}$ of cimetidine daily for eight-week periods, Wesdorp et al $^{5}$ found a significant improvement in the gross endoscopic and histopathological evidence of oesophagitis. We used a much longer period of treatment and found clear evidence of improvement in oesophagitis as judged by gross appearance but not by histopathology. This suggests that, although symptomatic relief is rapid, improvement in oesophagitis takes much longer.

In contrast with the improvement in oesophagitis we found no reduction in the need for dilatation of peptic oesophageal stricture. The explanation for this apparent discrepancy may be that the six-month treatment periods were too short for any reduction in the rate of stricture formation to become apparent, and certainly several of our patients who continued to take cimetidine after the trial was over needed fewer dilatations. Alternatively, agents other than gastric acid may be responsible for stricture formation. Reflux of bile and duodenal or smallintestinal contents is a recognised complication of operations 
for peptic ulcer, and the three patients in our study who had undergone vagotomy and drainage or gastric resection all needed frequent dilatations during both placebo and cimetidine treatment periods. Since our results show that cimetidine benefits oesophagitis, however, it seems reasonable to hope that a longer period of treatment might lessen the need for dilatation.

We are indebted to Dr P D James for the histopathological reports, and to Smith Kline and French Laboratories Ltd for the placebo and cimetidine tablets.

\section{References}

${ }^{1}$ Atkinson, M, and van Gelder, A, American fournal of Digestive Diseases, 1977, 22, 365 .

2 Bennett, J R, Martin, H D, and Buckton, G, Cimetidine, conference proceedings, Westminster Medical School, p 147. Edinburgh, Churchill Livingstone, 1978.

${ }^{3}$ Behar, J, et al, Gastroenterology, 1978, 74, 441.

4 Powell-Jackson, P, Barkley, H, and Northfield, T C, Lancet, 1978, 2, 1068

5 Wesdorp, E, et al, Gastroenterology, 1978, 74, 821.

${ }^{6}$ Petrokubi, R J, and Jeffries, G H, Gastroenterology, 1978, 74, 1077.

(Accepted 20 fuly 1979)

\section{SHORT REPORTS}

\section{Babesiosis in man: a case from Scotland}

Babesiosis, a world-wide tick-borne protozoal disease of wild and domestic animals, has occasionally infected man, and cases have been reported from both Europe and America. ${ }^{1}$ The Old World cases, often associated with cattle babesiosis, have generally affected patients who have had splenectomy and the outcome has often been fatal; the American cases, in patients with intact spleens, have been centred on the Island of Nantucket and appear to be a less serious form of the disease associated with a rodent babesia. We summarise here the details of the first recorded case of babesiosis in the United Kingdom; the case will be reported fully elsewhere. ${ }^{2}$

\section{Case report}

A 34-year-old accountant who lived near Inverness contracted Hodgkin's disease in December 1974. A splenectomy was performed and treatment with telecobalt radiation undertaken. He remained well until August 1977, when a recurrence of Hodgkin's disease again required treatment by irradiation.

In August 1978 he was admitted to Raigmore Hospital, Inverness, with a three-day history of tiredness, malaise, vomiting, diarrhoea, and a diminishing output of dark red urine. On admission his skin was dusky red, the conjunctivae icteric, the pulse rate 120 /minute, and the blood pressure $130 / 80 \mathrm{~mm} \mathrm{Hg}$. There was a normochromic anaemia- $\mathrm{Hb} 8.9 \mathrm{~g} / \mathrm{dl}$, which fell to $7.3 \mathrm{~g} / \mathrm{dl}$ within the first day. The total white cell count was $19.4 \times 10^{9}$ $\left(19400 / \mathrm{mm}^{3}\right.$ ) with $80 \%$ polymorphs. ESR was unreadable owing to intense haemolysis. Serum concentrations were: bilirubin $95 \mathrm{micromol} / 1(5.7 \mathrm{mg}$ $100 \mathrm{ml})$; potassium $4.8 \mathrm{mmol} / 1(\mathrm{mEq} / 1)$; and creatinine $501 \mu \mathrm{mol} / 1(5.5$ $\mathrm{mg} / 100 \mathrm{ml})$. Blood film showed heavy infestation of erythrocytes by an intracellular parasite.

The patient was transfused with concentrated red cells and his renal function closely monitored. The possible use of antibabesial drugs available in veterinary medicine was considered and a supply of diminazene (Berenil) arranged. In the interim intensive antimalarial therapy, initially with quinine intravenously followed by chloroquine intravenously and pyrimethamine, $50 \mathrm{mg}$ orally, was started. He appeared to improve and there was an appreciable fall in the degree of parasitaemia. Nevertheless, renal function progressively deteriorated and he was transferred to Aberdeen for haemodialysis. By then his blood urea concentration was $64 \mathrm{mmol} / 1$ (384 $\mathrm{mg} / 100 \mathrm{ml}$ ). Two haemodialyses were successfully completed but cardiac embarrassment developed owing to a pericardial effusion and, although $500 \mathrm{ml}$ of blood-stained fluid was aspirated, his condition rapidly deteriorated and he died. Death was attributable to cardiac tamponade; at necropsy, the pericardial cavity contained blood clot and serosanguinous fluid. Uraemic pneumonitis and pleurisy were present. There was a para-aortic lymphadenopathy and splenunculus at the tail of the pancreas. Histological examination showed Hodgkin's disease in the lymph nodes and the splenunculus; the kidney presented acute tubular necrosis with extensive haemoglobin cast formation in distal tubular and collecting ducts.

Four $\mathrm{ml}$ of heparinised/EDTA blood sent to the Agriculture Research Institute at Compton, Berks, was inoculated, intravenously and subcutaneously, into a splenectomised bovine and produced a Babesia divergen parasitaemia at its maximum (9/1000 infected cells) seven days later. The parasite was also succcessfully isolated in gerbils (Meriones unguiculatus) Subsequent serological tests carried out at the Central Veterinary Laboratory at Weybridge, Surrey, confirmed that the parasite was $B$ divergens. ${ }^{2}$

\section{Comment}

The patient who has had a splenectomy appears to have lost his most effective protection against these parasites ${ }^{3}$ and now that splenectomy is commonly performed a considerable number of people must at times be at risk-for example, on outdoor holidays. In blood films it is easy to confuse babesia with malaria parasites, and antimalarial treatment has been used in several of the cases recorded. A trial of diminazene and pentamidine, which are effective in animals, ${ }^{4}$ would appear to merit consideration in severe cases of human babesiosis. The extent to which $B$ divergens may give rise to subclinical infections is unknown but the possibility may be worth considering in patients with fever where exposure to ticks has, or could have occurred.

${ }^{1}$ Dammin, G J, Seminars in Infectious Disease, 1978, 1, 169.

2 Entrican, J H, et al, fournal of Infection, 1979, in press.

3 Garnham, P C C and Voller, A, Acta Protozoologica, 1965, 3, 183.

4 Miller, L H, et al, Annals of Internal Medicine, 1978, 88, 200.

(Accepted 13 fuly 1979)

\section{Raigmore Hospital, Inverness IV2 3UJ}

J H ENTRICAN, BMEDBIOL, MRCP, senior registrar $\mathrm{H}$ WILLIAMS, MD, consultant microbiologist I A COOK, MD, FRCPATH, consultant haematologist W M LANCASTER, MB, FRCP, consultant physician

J C CLARK, MB, CHB, lecturer in pathology

Ministry of Agriculture, Fisheries and Food, Central Veterinary Laboratory, Weybridge, Surrey

L P JOYNER, DSC, FIBIOL, senior research officer

ARC Institute for Research on Animal Diseases, Compton, Near Newbury, Berks

D LEWIS, BSC, senior scientific officer

ONE HUNDRED YEARS AGO An application of a very singular nature came before the Bridgnorth Town Council at a recent meeting. The Medical Officer of Health (Mr Mathias), commenting on the health of the district during the first quarter of this year, said that he had no report to make and no sanitary defects to bring under their notice. The only complaint he had was, that he was receiving too much money for the work he did. He therefore proposed that his salary should be reduced by $£ 10$, thus making it $£ 20$ instead of $£ 30$ per annum. Mr Mathias can, we think, hardly be serious; $£ 30$ is by no means an exorbitant salary for looking after the public health of a community of six thousand persons, even if, which is by no means the case at Bridgnorth, the vital statistics of the place showed it to be exceptionally healthy. Mr Mathias has himself said that he does not believe it is right for him to take public money that he does not earn; and we trust that, on reconsideration, he will see that the trues economy to the district would be, not to accept less remuneration, but really to earn, by more vigorous supervision of the district, his present salary. (British Medical fournal, 1879.)

\section{Correction}

Herpetic proctitis and sacral radiculomyelopathy

We regret that a printer's error occurred in the title of the short report by Mr Samarasinghe and his colleagues (11 August, p 365). "Sacral radiomyelopathy" should have read "sacral radiculomyelopathy." 